\title{
MASK AS AN EPIPHANY: AN ANALYSIS-WESTERN, EASTERN, AFRICAN ART FORMS
}

\section{V.L. PARVATHY, SWATHY S. DINESH \& ARUN.S}

Research Scholar, Department of English, Amrita school of Arts and Science, Amritapuri, India Research Scholar, Department of English, Amrita school of Arts and Science, Amritapuri, India Assistant Professor, Department of English, Amrita school of Arts and Science, Amritapuri, India

\begin{abstract}
Mask as an embodiment of culture tradition and art. Mask plays a vital role in art forms and in human life. Mask creates a person to transform an individual. In olden days mask play an important role in the field of drama. Artist they use mask to depict tragic elements to the viewers. Orient art forms they are usually related with rituals and cultures, they use mask to express the emotions portrayed by the characters which they are enacted. In orient art forms mask are made with synthetic product and color that are painted in the face. In occident art form it is entirely different way of making mask they carved the shape in bones, wood or in artificial things and artificial colors were used while using this they can hide their real identity through this paper, we make an analysis of art form of Western, Eastern and African and the influence of mask in these places. Also we make conclusion that how it related with human emotions and the varying features of mask.
\end{abstract}

KEYWORDS: Embodiment, Mask, Orient, Occident, Synthetic

Received: Jun 08, 2020; Accepted: Jun 28, 2020; Published: Sep 03, 2020; Paper Id.: IJMPERDJUN20201038

\section{INTRODUCTION}

The antecedent of the term mask is ambiguous. Literally mask means something that serves to conceal from view or disguise. The word mask has a foreign origin. Its antecedent is perhaps associated with Arabic term maskharah which means to transform or falsify or from French term masque or Italian word maschera or the Spanish term maiscara or Medieval Latin masca. Mask is an iconic sophisticated theatrical metaphor that conveys connotative and denotative, socio-cultural themes which work beyond geo-sociopolitical boundaries or constraints of the world. Functionally masks have therapeutic, socio-religious, festive, theatrical, as well as funeral and commemorative, representational, emotive and indexical uses. External and internal Meta the siophobia compelled people to create masks which intertwined natural or physical then supernatural or metaphysical spheres which remain mysterious to human beings. Mirror image of human psyche which generates photographic recreation of the natural world through exact mimicking or other representational forms is vividly portrayed through masks which embedded with customs and music. During folk and religious pavements, rituals and sophisticated theatrical performance with religious affiliation masks acts as distinct metaphorical disguise that embodies multiple identities through which ordinary individual has potential or capability to assume dual personality by subjugating or concealing an individual's identity and transcending his physical self by assuming characteristics of personality of the mask lend to him that evokes intimate emotional responses and visual focus from spectators.

"After covering the body and its colors by means of paints and cosmetics an actor should assume the nature of the nature of the person whose character he represents " 
( Man Mohan Ghosh, Natyshastra, chawkhamba Sanskrit series office1907, 2003, chapter 23, costumes and makeup,p.423.)

Mask is aesthetically sublime and culturally functional symbol which is amalgamation of retaining and wielding power employed to convey plot embedded with natural process function by confronting equilibrium between natural and worldly spirits. Based on neocultural ideology masks possess magical powers to transcend from individual to supernatural being devoid of which individuals were mere mortals'. While performing religious ritualistic performance, socio-rituals, ceremonial functions masks which personify human message and constituents which provide a sense of continuity. External detachable variety mask portrays stable exaggerated performers emotions throughout which restrict performers emotion devoid of age and gender constraints to the spectators by providing bewilderment and it could be a vivid facial painting and design. To suit distinct situation human beings embody multi-dimensional personality layers with multiple selves. In psycho synthesis, a method by Roberto Assongoli proposed multiple personality enclosed or embedded in an individual who switches consciously and unconsciously devoid of knowing. Britton little, a personality psychologist also established nuances of multiple personality layers (biogenic, sociogenic, idiogenic) which resembles with Japanese ideology regarding human possessing three faces the first faces which is highly pretentious evident in social sphere whereas second face is prominent in intimate circle (family, friends) and third face is your actual self which is deeply buried or hidden within oneself. Similarly mask can conceal and modify minimized number of conventional identity metaphors of core identity which literally represented transformed identity of performers enabling deeper self-realization through dissociation and objectivity which allows them to transcend monotonous daily inhibitions and remind them of mutility and chaos of montane reality.

"Man is least himself when he talks in his own person

Give him a mask and he will tell you the truth

(Oscar Wilde, The critic as an Artist)

Indian, Chinese, Japanese, and Burmian theatrical masques had same uses.In India masks along with costumes which have symbolic association with mask imagery makes appearance complete. Three distinction of chaau masks have symbolic association with past, present and psychologically the spectators became associated with past. Though we can't traceoutany Photographic recreation of western masques in Indian artistic tradition, we can figureout Indian performing art forms resembling to masque in terms of origin, constituents like colour symbolism, dances, dialogues. Bronze, golden masks of dieties used in temple during special occasions, Roman wax mask, Venetian mask and English designed mask used for English entertainment from miming and Elizabethan masks made out of plaster of Paris have special significance..In terms of procession masques and kathakali is structurally equivalent. In terms of procession, grand entry and going out both masques and kathakali are structurally similar. In Context of kathakali stage before procession contain Arangukeli, thodayam, keliand the main masque include interludes. In correspondence with going out in masque kathakali contain mangalslokam and main masque is explained or interpreted with songs, hymns, even kathakali encompass songs and hymns between actions of main story, which often start withmanjuthara.Music and literature mythologies are equally blended in both cases. The elaborate facial painting with costumes gives impression of mask in case of kathakali even though there is no actual mask in kathakali.. In association with symbolic significanceyakshagana in Kannada can be compared with masque and three types of performing arts in Bali (topeng mask drama, waving wong mask drama and jauk dances),srilankankadyandance, Japanesekudubi and godaku dance can be compared with that of masque and thematic 
elements of performing arts in Bali is derived from Ramayana, Mahabharata and similarly Bhaona, masked dance drama of Assam have association with mythological characters in Krishnanattam, which encompass masque elements. Western masque is enacted during twelfth night or special occasions similarly Seraikalchaau is patronized by members of royal family.. Both western masque, which have dramatic and allegorical bearings and Indian masked performance having dramatic and ritualistic bearing performed during religious ceremonies both consist of dramatic devices which explore so called "collective unconsciousness" (inner depth of human psyche ).Mahout distinction between eastern and Western art forms is that eastern masked art form is performed in association with religious functions whereas western is performed during special occasions and ceremonies. Primary colour schemes, pattern, structure, head hears remain intact whereas the characters are categorized into six types such aspacha(green),katti(knife), kari(black), Thaadi(beared), Minukku based on predominant colors portrayed on face which hold symbolic meaning (indicate each characters basic nature).It contain three to four hours complete theppu or facial painting done by artist himself and chutti done by chuttikaran using herbs like chenchiyam to protect skin from burns, powdered chaayilam and manayada ( red and yellow colored natural substance)mixed with oil rice flour and lime mixture for white, neelam, mnayola mixture with coconut oil for greencolour, saffron, punyahachunda, keeradam,is made out of light weighted medical wood kamizhu and golden foil paper, peacock feather paccha or green is used to portrays heroes, demigods, divine beings, satvik characters like Rama, Krishna who is devoid of fear calm, chivalric and good natured kathi or knife represents highborn characters (symbolized by basic green facial painting) treacherous and aggressive character from Hindu mythology with white knobs on nose tips and forehead painted knife or remark which appear like upturned moustache to exaggerate its evilcharacteristics. Thaadi or beared conventionally potrays human or demon antagonist encompassing rajaswik nature. It is further categeorized into chuvannathaadi or red beared (red beared characters used to wear red jacket. Then head gear resembling wathik characters like Krishna, lava, kusa) represented by Bali with upper portion painted black and red based lower portion and karuthathaadi (black beared) represented with black colored base dominates in theppu with white and red designs and costumes and the white beared (vellathaadi characters used to wear white jacket) is represented by Hanuman(half human god, docile characters)which makes us act furious occasionally. Kari characters represents tribals for example Siva disguised as kirata having black beared with white and red designs in cause of theppu. minukku typically were presented by Brahmins, women, sages, messanger shows high spirited revelations, gentleness is potrayed using yellow facial makeup which represent wonder or adhbuta.

Theyyam is a spectacular oldest mystic ritual held yearly from October to may having four hundred varieties including vishnumoorthytheyyam, Muchilottbhagavatitheyyam, sreemuthappantheyyam (thiruvappan and valiyamuthappantheyyam performed once in a year.Padamsdakkybhagavati(myth is that Nileswar raja seeks the help of padamadakkybhagavati to escape from invading army thereby goddess swendpadamadakkybhagavathy for this endevour thereby army retrieve), Kathivanorveeranpadayani (enacted in remembrance of great warrior), Shasathappantheyyam(performed in ancestoral house or shrine), Padikuttiamma (performed in muthappanparasanikadavu temple), Gulikantheyyam (represents Yama), in which facial painting or masks and costumes prepared using combination of indegenious pigments that is primary and secondary colour combinations varies based on myth employing Dravidian and tribal characteristics performed in ancestoral house and shrines such as madam, kalari, thara,palliyara (and weapons placed and work shipped as an embodiment of divinity) in Kasargod., wayanad, vadakara, koylandy, kodangu of Karnataka by lowercaste members like velans, malayans, through impersonating god and goddesses that transforms to the status of a particular deity accompanied by muscial instruments like chenda, kuzhal, 
veekni, vocal recitation in the initial sections.vellatam, kozhipuspam, kottumpurikam, prakkethezuth, vairradam, kottaram are distinct variety of face painting. In theyyam four hundred variety of face painting known as mukazezuth colors intricate meaning using contrasting yellow (turmeric), orange, black (ink) ,along with oolachayamonaments carved out of wood, breastplate, hood, fabric. Of attire, bracelet differs from each variety. It has extensive face painting face painting with intricate lines and patterns drawn using coconut leaf white to a fine point. Based on developmental forms and shrine rights it is further categorized into three in which first in performed by velans, kopalan, mayilon, parayan,. Community make use of natural and readily available products like seasonal flowers, turmeric, and ricepaste, areca sheath, black collected from smoke of seasae oil lamp and quick lime utilized for body and and facial painting and tender coconut leaves, banana leaves without elaborste nor simple costues and simple facial painting with base facial colors having designs and patterns.. Second cateogeory is performed by paravan, Malayan, munnatam, anhuttam community uses manayola (yellow) and chaayilyam (red) for elaborate facial painting and designs nstural products like silks, cotton, wooden ornaments decorated with glass beads or golden foil. Third cateogeory is kolam such as muchilottbhagavathy, kathinoorveeran, Vishnu moothy, pulingorukannan (tiger god) is performed.Further distinction can be implemented regarding nature of workship such as theyyam of goddesses, god, ancestors, hero,heroins, animals, spirits, devils. In krishnanattam resembles with kathakali in terms of makeup, costumes, ornamentsabdwith theyyam in terms vibrant facial painting and designs encompassing eight performance such as kamasavadam (characters Krishna and balarama), Avatharam(brahma and bhumidevi), kaliyamardanam(krisna, balarama, nanda, upananda), raasakreeda (Krishna), Banayuddam( Krishna, sathyabhama and garuda), Vividavadham (contains two purappadu first by balarama and wives second by Krishna, bhims and arjuna), Swargaarohana (Krishna and balarama) accompanied by playing drums maddhalam), gong (changala), cymbols (elathalam). It encompass five types of facial paintings, potrayed in face hldsynmbolic meaning (indicate character type) paccha (green) is used for Nandagopa, Vasudeva, Kamsa, uddhava, muchakunda, dandakavaktha, rkumini, arjuna,janayu whereas for Radha, Bhnidevi, sathyabhamachuttia long with green facial painting is used. Characters like rukmini, sisupala(green),jarasandha which epress anger are painted dark green whereas Krishna's face is painted light green. Krishnanattam characters are categorized under titles paccha, pacha with hair, pacha with chutti, pazhuppu,chempazhuppu, kathi, minukku, pazhuppu (orange) used for balarama,siva, bhima and minukku (for all women characters including sathyabhama).Face painting is categeorized as paccha,pazhuppu,kathi,minukku,kari(black).Kathi facial makeup for royal characters, toddy topper whereas kuchela have no facepainting. Among eight performance kamasadhavan, Rasakrida have no mask whereas green colour is attributed to Dharmaja (swayamvaram),kanda(have bigger chutti than Krishna, eyebrows, castemark also differs) yamadharma (dark green), sisupala, sankhachundan(there nose is painted with chutti white colour later painted red)are painted green then putaba(avataram), vivida (vividavadam),Gandhakarna, hunter(swargarohanam)to portray ferocity of character s then Balarama,bhimsena(dark red),narakasura(red beared)is painted pazhuppujambhavan have white facial painting to portrays hasta.Characters like yamadharma, vivida, narakasura, murasuran (banatudham). Brahma, jambhavan (swayamvara), Purana (avataram), Bakasuran (kaliyamardhanam) use external detachable mask along suitable attire.Manayola is basically used for face painting, while amalgamation of manayola and green colour gives blue colour whereas pazhuppu (light red colour)can be obtained by mixing chaayilyam with manayola. White chutti is compulsory for female characters traditionally sathyabhama and rukmini had comparatively smaller chutti resembling that of Krishna and face is painted with light red colour but in modern scenario they are categorised under minukku characters whereas Radha have patrarekha (Sanskrit) painted on face. Face painting in case of female characters has slight deviations. Symbolic meaning is attributed to colors for example red colour indicate roudram (terror),green 
indicate sringaram (sentiment of love), black indicate bhibatsam (terror), yellow indicate athbhutham (wonder),golden colour indicate veeram (courage), brown indicate karunam (pity),blue indicate (sobriety).kootiyattam is accompanied by musical instruments like mizhavu(PT shaped percussion instruments), idakka, kuzhithalam(pair of cymbals), kuzhal, Sanju is used.The facial painting ingredients include rice powder, redarsenic, turmeric Powder, oil black chaayilyam (vermilion), neelammanayola, chundapoovu, bamboo stick, crock, lime, coconut oil, redthechi flower, vazhanaru (thread of coconut stem)and have diverse performance structure attributing preference to character introduction elaborate story description and music. All the four modes of acting such as Vachikabhinaya (vocal delivery), Aharyaabhinaya (costumes and makeup) Angikaabhinaya, satvikaabhinaya. The painted face mask emphasis mindset or innate nature of super human character through colour schemes which is similar to costumes and makeup in folkdances like Theyyam and thirayattam which attribute special Kerala features in terms of design and application. Then noble characters uses green facial painting paccha, red lip, black eyes and eyebrows whereas wicked characters uses face painting paccha, red lips, black eyes and eyebrows whereas wicked characters uses face painting called Kathi types uses red and white colour in this face painting mKari type is used to portray demons and body is painted entirely black with red lips, white marks on forehead. Entirely different face painting is used to portray animals which are further classified into two based on characteristics of animals. Minukku character types have simple make up is used to potray animals which is further classified based on characteristics of animals. Minukki character types have simple and shiny makeup is used to potray female and saints. Vidhushaka, animal's sages, birds, animals and other characters uses distinct variety costumes. The paccha characters are SriRama, Vibhishana, Arjuna, Lekshmana and Ravana belongs to Kathi character types, stage manager, Bhīma, Vidhyadharasamavarana belongs to pazhuppu (orange and red character types),narada, jambhavan etc. belongs to minukku character retype. sugrreva belongs to category entitled karuthathaadi, Bali belongs to chuvannathaadi (red beared). Hanuman belongs to vellathadi character types and surpanaka belongs to Kari(black character type) vidhushaka's body (face, arm, chest) is painted with white paste which is entirely differ from other that of other characters. There are distinct varieties ofpadayanisuch as elathoorpadayani which consists of kolams like ganapati, pischachu, marutha and its distinct variety like kootamarutha, rudramarutha, kuthira, pakshy, sundharayakshy, erinagayakshy, Mayayekshy,arakkiyekshy, athathayekshy, Madan, karinkali, kaaalankolam, bhairavikolam, mangalabhairavi, kaaanjirama, sharkarkudam, etc) Kootayadipadayani (performed yearly once that is mainly eight days of performance in Kottayam and pathanamthitta bhagavati temple.Major kolams performed are ganapatikolam, parki kolam, sundharayakshy, jalankolam, kuthirakolams), Kadamanittapadayani (it's performance encloses distinct traditional performance and kolams like ganapatikolams,kuthitlra,bhairavi,sundharayakshi,narkiyakshi,marutha,kalamadan and kalankolam performed start from month of January to February) karmpalapadayani (performed once in five years), kallooparapadayani (kolams of yekshi,pakshi,marutha,jalan and bhairavikolams is performed between every February to march),kadalimangalampadayani(in this kalayakshykolam is performed in ten day long festival between April and march conducted by inhabitants of two Karas), kottangalpadayani or ettupadayani (eight day lasting performance conducted by inhabitants in kottangal and kulathoor between December and January which starts on third day of ganapatikolam after chootuvaippuand ends with performance of kalankolam and valiyapadayani(last two days)in which bhagavati is staged.).kunnamthanampadayani(devatakolam resembling madathilKavibhagavati and ambarayakshykolams were performed as a part of pathamodayamaholsavam and in pathanamthittamadathilKavibhagavati temple between Malayalam month of Medan three to ten).pooradampadayani (performed in sixteenth day of neelampoorpadayani).Neelampoorpadayani (it's distinct from original form of padayani 
performed in Neelampooralapuzhapallibhagavati temple) Thangelibhagavatikolamthullal including rhythmic footstrides,legmovements, costumes, singing, structure of kolams, dressing and adorning styles is different for each kolams. kolamezuthu (face painting)using tender coconut leaves, charcoal paste, manayola(silks). Holding the kolams of direties such as pischachu, Madan, marutha, distinct varieties of kolams including vellayumkariyum, ganapatikolams, kalankolams, pakshikolamvellayumkariyum In this kolam half of the artist's face is painted dark and other half white symbolically representing shift from darkness to light evolution of this kolamisn' traced out. Ganapatikolam and ganapati Jacquelyn is distinct in costumes even if it sounds same,skirt wrapped around red silk is made with tender coconut leaf there are rounded lines towards the bottom and nagappathy on the cap whereas in ganapatipischachukolam which is taken out of single areca leaf sheath top of which resembles thrisul wearing coconut leaf skirt and holding lighted torch. This is an extinct kolam with round face cut out of areca sheath and artificial eyes is painted along with fixed protruded teeth.kanchanamany, tender leaf Kurt wrapped over the redsilk. They perform five adavu and kalayam is performed in between.Kanjaramakolam Eighty one sheaths is used in this kolam in which elephant and bhairavi is painted in ear. yekshykolams in padayani have it's on distinct characteristic features, expression, mukathu (facial painting)and in mode of enactment.Sundharayekshy in this colorful waist silk, chest shield (nenjumala) tender coconut palm leaves on figures are featured on sundharayekshykolam. Ananthayakshykolam have tender coconut leaf nail and bangles, chest shield (nenjumala), waists heild made out of nine areca sheath and is tied fast to the performers chin, Kanchana on legs, protruded teeth and face painting is done by manayola and chaayilyam (green colour), charcoal paste. Amara yekshykolam resembles that of ananthayekshy and padyottamkolam standing on a moving chattam (wooden frame) assumes the style of flying goddess using appropriate body dynamics. This kolam have three or five charcoal painted face,protruded teeth hair covering back, sword in the left hand, Kanchana I tender coconut leaf skirt wrapped over silk skirt. kalayekshikolam is made out of fifty one areca sheath in which coconut leaf skirt is wrapped over red silk. Maya yekshi (the dirty of destruction), Arakkiyekshy, Erinagayekshy have its unique and dance aeps still exist in Erinagayakshy whereas kolam dances extinct in ayaliyekshy, paranjayayekshy, karinagayekshy. pakshikolam is performed as a part of sacrificial offering conducted to save newborn children from ill effect of certain birds which used to utter special sort of sound near house of newborn babies. The beak is made out of areca sheath; tender coconut leaf skirt wrapped around waist.Kuthirakolam is performed to hint trade relation between Kerala and Arabs. Artificial moustache and bearded as well as previously prepared horse model is attached to artist's waist by means of string passed over artist shoulder and hair is covered using white clothes.Maruthakolam(small pox diety) it consists of distinct variety of marutha as anamarutha, pachamarutha, neelayekshymarutha. In maruthakolam performer used to wear twigs of ilanjitree.Madankolam (protector of cattles) which is further categorised into pullimadan (pullimadan have painted pully or dots),Thoppi Madan (wears areca leaf sheath cap),kaalamadan(commander of time) vadimadan (used to hit ground with stick while vigorously dancing looking at sky) chest sheild, third eye and poonool is painted and topmost part of kolam resembles to shivamudi. The customs and traditions is distinct in three styles of chaauout of purilala and serakeilla style uses masks during community celebration devoid of ceremonial and ritualistic affiliation performed during night time blending marital practices and mock combat technique.SeraikellaChaau patronize by rulers of Seraikella is popular in West Bengal and seraikella district of odhisa. Mayirbhonychaau doesn't use mask during dance while other two uses giants of birds and animals along with village women chorus.SeraikellaChaau uses symbolic masks whereas purialachaau extensive masks including costumes. MayrbhanyChaau technically resembles with seraikellaChaau. The masks of hindu god and goddess is made by patterns in puriala district of West Bengal. MayirbhonyChaau is similar to English masque performed marriage celebration and Christmas Eve where as other two 
are theatrical mask. Kummatikali is colorful dance mask dance prevalent in northern district of thalla and thamma with externally attached mask attributing toothless open mouth appearance considered to be symbolic mother of entire human beings walk in front of procession. In case of African mask uses numerous materials like clay, paperpul, wood, metals, bamboo stick, tin, leather is used to make masks in India whereas in Africa mask, which symbolizes spirits is made out of saga tree wood, bone, textile, feather having various geo metrical forms and style usually worn by performers used in masquerades and religious ceremonies, rituals to ensure good harvest while wearing this performer invokes ancestral spirits or supernatural beings by subjugating their identity the performer is assumed to be capable of communicating with supernatural being or spirits envisaged in the mask. Majority African mask is associated with spirits deceased creatures important to certain ethic group and family and is kept in specific building and is taken out during specific occasions but is not allowed to touch. There are simple as well as elaborate African mask decorated with shells, feathers, mask curved out of wood having painted polished surfaces. Religious drama in China use masks made of paper Mache whereas secular drama makes use of face painting and costumes which resembles masks like kabuki (traditional Japanese dance drama which amalgamates music, dance, mime, staging, costumes)

The actors in China used to wear fanciful masks while performing sacred drama and are highly ornamented with elaborate headgears, ornaments. In theatrical performance like eating Wong On java and Bali they use wooden masks and it's stories are part of ancient Sanskrit literature especially that of Hindu epics and the vividly colored mask are made up of wood, leather, horsehair then metallic and glided paper accoutrements and are ordinarily held in teeth by means of leather. Occasionally an actor interrupts the unseen narrator who is vividly narrating the play. The theatrical mask used in java is exceptional. The khon masked dance drama in Thailand represent height art having didactic functions that depicts the glory of Rama(including their journey in the forest and his army of monkeys, fight with the Thosakan ) and incarnation of Lord Vishnu by incorporating musical, literary, ritualistic, dramatic handicraft elements to greater extend is similar to Indian dance dramas using mask which have religious affiliation (themes of which is taken out from mythological stories from epics).In Tibet (China)sacred dance dramas such as dance of tiger devil is performed in specific period accompanied by priest or lemans wearing masks of deities and demons like the mask made up of paper Mache, cloth and gilt copper used in mystery plays. In Indian states such as Bhutan and Sikkim where wood is abundant durable mask is curved out of wood whereas masks used in dance dramas in Himalayan regions fantastically painted and is decorated with wigs made from vividly painted yak tail. Noh dance drama in Japan have 125distinct varieties of masks which is rigidly traditional and are classified into five distinct gendered such as Old person(men and women ), god, goddesses, devils, globins and the mask is made out of wood quoted with plaster which is glided. Similar to kathakali symbolic meaning is attributed to colors in order to represent various character types. In Noh, with contradiction to traditional aspects white face painting is used to portray a correct ruler and red signifies a righteous person whereas in kathakali red is used to signify villain characters then a black mask is worn in Noh to represent. Though majority of this sort of art form extinct and loss it's originality it can be regarded as an embodiment of ritual's, traditions and culture prevailed in different countries and sub continents. There are external detachable mask which is made out of artificial things and can conceal or hide real identity and emotion in case of western masked art form and eastern art forms they use face paintings with natural ingredients that shows real emotions of performer. Eastern Masked art are related with some heroes, god or goddess. Each mask have its own story embedded with ii through which they potray emotions in accordance to the context, sometimes to conceal their own emotion and forget themselves. In this modern world the human society has no times to reveals their identity and their culture. In present scenerio, modern society is constructing and transmit dangerous form of pseudo culture to upcoming generation by 
convincing them that it's their native culture as a result they become unaware about the tradition and culture and this pseudo culture is used to promote Tourism.

\section{REFERENCES}

1. Raghavan.M.D.1964, India in Ceylon History, society and culture, India: Asia publishing House, 129.p cited in M.H Goonatilleka, 1968.

2. Man Mohan Ghosh, Natyshastra, chawakhamba Sanskrit series office 1907, 2003, chapter23,costumesand makeup,p.423.

3. Pal, A.k. Chhau Dance and Chaitra Parva of Mayurbhanj. Ibid, p.1920.

4. Odoh, George C., Nneka S. Odoh, and Ekene A. Anikpe. "Waste and Found Objects as Potent Creative Resources: A Review of the Art is everywhere Project." International Journal of Humanities and Social Sciences 3.6 (2014): 114.

5. Finely, Carol. The Art of African Masks. Minneapolis: Learner, 1999.

6. Krishnattam, Dr. MathaBush AshtonSikora and Robert P.Sikora, Oxford and IBH publishing PVT. Ltd, New Delhi, India (1993).

7. https://en.wikipedia.org/wiki/Nuo_opera.

8. http://www.teachinghistory100.org/objects/about_the_object/greek_theatre_mask.

9. Edet, Itari Paul, Beshel Cecilia Akpan, and Okeme Isaac. "Indigenous communication media and utilization of development information in rural communities of south-south Nigeria." International Journal of English and Literature 5.1 (2015): 8596.

10. https://www.britannica.com/art/mask-face-covering/Theatrical-uses

11. https://thegreekdesigners.com/2016/03/07/drama-masks-thalia-melpomene/

12. Raihanath, M. P. "Strategic Marketing How Corporates Build Competitive Advantages." International Journal of Economics, Commerce and Research (IJECR) 3.2 (2013): 3756.

13. https://broadwayeducators.com/classroom-and-rehearsal-mask-work-can-free-the-actors-body/.

14. https://en.wikipedia.org/wiki/Theatre_of_ancient_Greece.

15. IRSHAD, MS SHAISTA, and Rashmi Gaur. "Construction of Sex, Gender and Class in Margaret Atwood's Alias Grace." International Journal of English and Literature (IJEL) 3.2 (2013): 117126.

16. https://en.wikipedia.org/wiki/Rabinal_Achi.

17. https://en.wikipedia.org/wiki/Traditional_African_masks.

18. https://costumes.lovetoknow.com/Elizabethan_Masquerade_Masks.

19. http://themascherade.com/contents/en-us/d5_Page_5.html.

20. https://www.britannica.com/art/gigaku-mask. 